\title{
STUDY OF INCIDENCE OF ANGLE RECESSION IN CLOSE GLOBE INJURY AND RISK FACTORS FOR DEVELOPMENT OF TRAUMATIC GLAUCOMA
}

\author{
Manjula. Y. M1, Suma C2 \\ ${ }^{1}$ Assistant Professor, Department of Ophthalmology, BGS Global Institute of Medical Sciences, Bangalore. \\ ${ }^{2}$ Senior Resident, Department of Ophthalmology, BGS Global Institute of Medical Sciences, Bangalore.
}

\begin{abstract}
To study the incidence of angle recession and risk factors for development of traumatic glaucoma in closed globe injury. MATERIAL AND METHODS: In our study prospective analysis of 25 patients with closed globe injury visited to BGS Global Institute of medical science, department of Ophthalmology, were evaluated for angle recession and risk factor for development of traumatic glaucoma were noted, that is increase in Intra ocular pressure (IOP) $>21 \mathrm{~mm}$ of $\mathrm{Hg}$ for minimum 3 months were diagnosed as Traumatic glaucoma.

RESULTS: The incidence of angle recession in our study conducted for 2 years from February 2013 to February 2015 was $68 \%$. The risk factors of developing traumatic glaucoma was high in patients with hyphema, angle recession $>180^{\circ}$, traumatic cataract and elevated baseline Intra ocular pressure.

CONCLUSION: Clinically not all patients with angle recession goes for traumatic glaucoma. Presence of hyphema, increase in baseline intra ocular pressure, angle recession $>180^{\circ}$ and increased pigmentation at the angle were associated with traumatic glaucoma after closed globe injury.
\end{abstract}

KEYWORDS: Closed Globe Injury, Angle Recession, Intra Ocular Pressure, Traumatic Glaucoma.

HOW TO CITE THIS ARTICLE: Manjula. Y. M, Suma C. "Study of Incidence of Angle Recession in Close Globe Injury and Risk Factors for Development of Traumatic Glaucoma”. Journal of Evolution of Medical and Dental Sciences 2015; Vol. 4, Issue 89, November 05; Page: $15410-15413$, DOI: $10.14260 /$ jemds/2015/2197.

INTRODUCTION: Trauma is a common cause of preventable ocular morbidity, commonly occurs in young adults.1,2 Traumatic glaucoma after closed globe injury is a major concern because many cases are not diagnosed and not followed up. Most of it is diagnosed after irreversible glaucomatous optic nerve damage.3,4 Angle recession is strongly associated with traumatic hyphaema with studies reporting a $60-100 \%$ incidence. ${ }^{5}$ A $3.4 \%$ incidence of glaucoma after blunt ocular trauma has been reported during 6 months follows up. ${ }^{6}$ and up to $10 \%$ during the 10 years after trauma. ${ }^{7}$

The aim of this study was to evaluate prospectively the incidence of angle recession and risk factors for development of traumatic glaucoma in closed globe injury.

METHODS: 25 patients with closed globe injury visited to BGS GIMS, Ophthalmology department, were analysed prospectively from February 2013 to February 2015 and are followed for 2 years were included in our study for evaluation. Ethical committee clearance from the institution was obtained.

Details of ocular injury like mode of injury, duration of injury any medications taken before and family history of glaucoma are noted. Detailed ocular examination of both eyes were performed including best corrected visual acuity, slitlamp biomicroscopic examination, intra ocular pressure Angle evaluation by gonioscopy using Zeiss goniolens was

Financial or Other, Competing Interest: None.

Submission 13-10-2015, Peer Review 14-10-2015,

Acceptance 15-10-2015, Published 03-11-2015.

Corresponding Author:

Dr. Manjula. Y. M,

M-Block, Apt. No. 701, Brigade Gateway,

Rajkumara Road, Malleswaram,

Bangalore-560055.

E-mail: drmanjumahesh50@gmail.com,drsumi13@gmail.com DOI:10.14260/jemds/2015/2197. done. Gonioscopy was performed after 3 weeks if hyphema is present. Extent of angle recession, were noted and graded as $<90^{\circ}, 90^{\circ}-180^{\circ}, 180^{\circ}-270^{\circ},>270^{\circ}$. Angle pigmentation were noted and graded as 0 (no pigmentation), 1 (Faint), 2 (Average), 3 (Heavy), or 4 (Very heavy).

Exclusion criteria were an open globe injury, primary open angle glaucoma and secondary glaucoma. All patients were followed every 1 month for first 3 months, every 6 months for next 18 months. At each visit best corrected visual acuity, applanation tonometry and thorough anterior and posterior segment evaluation were performed. Humphrey field analysis (24-2) was recorded in patients with best corrected visual acuity $6 / 6$ and IOP $>21 \mathrm{mmof} \mathrm{Hg}$. Patients with hyphaema were examined every 15 days to monitor the intra ocular pressure.

Patients with post traumatic uveitis were treated with short course of corticosteroids for 3 weeks. For an elevated IOP $>21 \mathrm{~mm}$ of $\mathrm{Hg}$ at the end of 3 month, they were treated with topical $\beta$ blocker timolol $0.5 \%$ twice daily, brimonidine $0.2 \%$ and latanoprost $0.005 \%$ once daily. Eyes with an elevated IOP $(>21 \mathrm{mmHg})$ and requiring glaucoma therapy for at least 3 months after closed globe injury were diagnosed as having a traumatic glaucoma.

RESULTS: 25 patients with closed globe injury followed for 2 years, who fulfilled inclusion criteria for the study, after taking their informed consent for examination were reviewed. Base line IOP $>21 \mathrm{~mm}$ of $\mathrm{Hg}$ were measured in $48 \%$ of patients (Table 3). Out of $48 \%$ of patients who had base line IOP $>21 \mathrm{~mm}$ of $\mathrm{Hg}$ at the end 3 month of follow up $32 \%$ of patients maintained the IOP $>21 \mathrm{~mm}$ of $\mathrm{Hg}$, they were treated with topical antiglaucoma drugs and IOP was controlled in all cases except two cases (Table 4).

GONIOSCOPY: Out of 25 patients examined 17 patients (68\%) were found to have varying degree of angle recession and 8 patients (32\%) with closed globe injury had no angle recession (Fig. 3, Table 5, 6). Out of 25 patient $24 \%$ had hyphaema and $20 \%$ had traumatic glaucoma (Table 7). 
Visual field analysis of 25 patients was done and none of them had visual field defect during two years of follow up.

In our study at the end of 2 years, out of 25 patients with closed globe injury 13 patients (52\%) were in younger age group between 10-20 years old. Male dominance was noted. Traumatic glaucoma i.e. IOP $>21 \mathrm{~mm}$ of $\mathrm{Hg}$ for more than 3 months was noted in 8 patients (32\%) out of 17 patients with various degrees of angle recession ranging from $90^{\circ}$ to $270^{\circ}$. All the patients with traumatic glaucoma had angle recession $>180^{\circ} .8$ and increased pigmentation at the angle. There were associated risk factors like hyphaema and traumatic cataract.

CONCLUSION: Glaucoma after blunt ocular trauma has 2 peaks of incidence, at less than 1 year and about 10 years after trauma. It is important to diagnose the risk factors for traumatic glaucoma so that ocular morbidity is prevented by appropriate therapy as early as possible.In our study out of 25 patients with closed globe injury $52 \%$ were in age group of 10- 20 years. Male dominance was noted. Angle recession of $>180^{\circ}$ was seen in $48 \%$ of patients with increase in angle pigmentation in $32 \%$, these were significant factors for occurance traumatic glaucoma.

Extensive pigment release during trauma clog the trabecular meshwork and mediate directly or indirectly causing changes in trabecular meshwork ${ }^{9}, 10$ which in turn may be the cause for decreased aqueous outflow by primary damage, inflammation or pigment release at trabecular meshwork. Girkin et al reported an incidence of angle recession of $8.6 \%$ in eyes without glaucoma and of $35.8 \%$ in eyes with glaucoma at 6 months.

Increase in Incidence of traumatic glaucoma seen in presence of hyphaema, and traumatic cataract. The clinical findings associated with traumatic glaucoma such as hyphaema, angle recession $>180^{\circ}$, displacement of lens and increased pigmentation of trabecular meshwork could be attributed to ciliary body damage.

The ciliary body injury leads to an inflammatory response not only at the site of injury but throughout ciliary body, iris and trabecular meshwork. Resolution of inflammation by fibroblastic response at ciliary body and trabecular meshwork decreases aqueous outflow and increase in intraocular pressure.
In closed globe injury with angle recession, not all the patients with angle recession go for traumatic glaucoma. Angle recession $>180^{\circ}$, high baseline IOP $(<21 \mathrm{~mm} \mathrm{Hg})$, hyphaema and traumatic cataract are risk factors. A long term follow up is necessary to see whether IOP decreases or increases after closed globe injury and to see whether eyes in the closed globe injury group would develop glaucoma.

\section{REFERENCES:}

1. Dandona L, Dandona R, Srinivas M, John RK, McCarty CA, Rao GN. Ocular trauma in an urban population in southern India: the Andhra Pradesh Eye Disease Study. Clin Experiment Ophthalmol. 2000; 28(5):350-356.

2. Salmon JF, Mermoud A, Ivey A, Swanevelder SA, Hoffman M. The detection of Post-traumatic angle recession by gonioscopy in a population based glaucoma survey. Ophthalmology. 1994;101(11):1844-1850.

3. Sihota R, Sood NN, Agarwal HC. Traumatic glaucoma. Acta Ophthalmol Scand. 1995;73(3):252-254.

4. Sihota R, Sood NN, Agarwal HC. Juvenile secondary glaucomas in India. Indian J Ophthalmol. 1991; 39(3):94-96.

5. Blanton FM. Anterior angle recession and secondary glaucoma: a study of the After-effects of traumatic hyphemas. Arch Ophthalmol. 1964; 72:39-44.

6. Girkin CA, McGwin G Jr, Long C, Morris R, Kuhn F. Glaucoma after ocular contusion: a cohort study of the United States eye injury registry. J Glaucoma. 2005; 14(6):470-473.

7. Kaufman JH, Tolpin DW. Glaucoma after traumatic angle recession: a ten-year prospective study. Am J Ophthalmol. 1974;78(4):648-654.

8. Kuhn F, Morris R, Witherspoon DC, Heimann K, Jeffers JB, Treister G. A standardized. classification of ocular trauma. Ophthalmology. 1996;103(2):240-243.

9. Richardson TM, Hutchinson BT, Grant WM. The outflow tract in pigmentary glaucoma: a light and electron microscopic study. Arch Ophthalmol. 1977;95(6):10151025.

10. Campbell DG, Schertzer RM. Pathophysiology of pigment dispersion syndrome and pigmentary glaucoma. Curr Opin Ophthalmol. 1995;6(2):96-101.

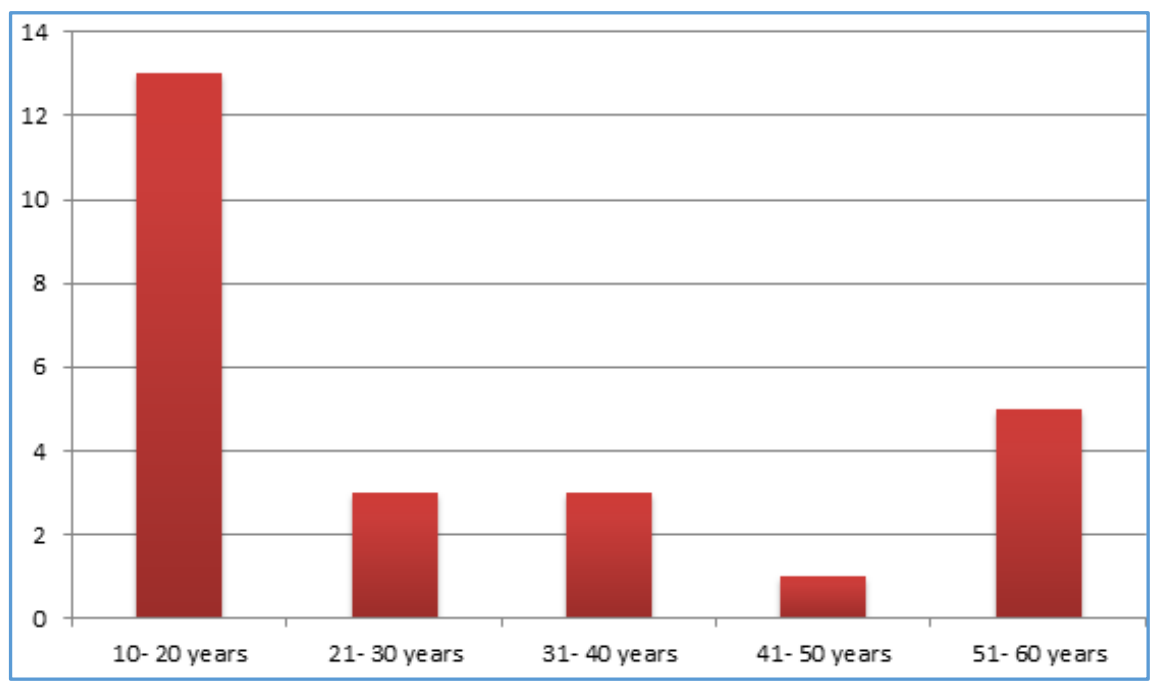

Fig. 1 : Age distribution 


\begin{tabular}{|c|c|c|c|c|c|}
\hline Age in years & $\mathbf{1 0 - 2 0}$ & $\mathbf{2 1 - 3 0}$ & $\mathbf{3 1 - 4 0}$ & $\mathbf{4 1 - 5 0}$ & $\mathbf{5 1 - 6 0}$ \\
\hline No. of patients & 13 & 3 & 3 & 1 & 5 \\
\hline Percentile (\%) & 52 & 12 & 12 & 4 & 20 \\
\hline \multicolumn{2}{|c|}{ Table 1: Incidence of globe injury with respect to age } \\
\hline
\end{tabular}

Fig. 1 and table 1 shows closed globe injury was common in younger age 10-20year group accounting for 52\% of the incidence

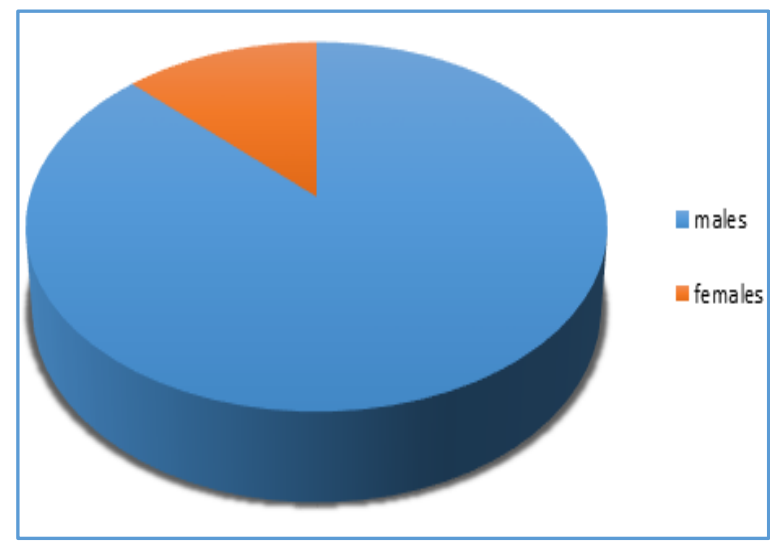

Fig. 2: Sex distribution

In our study closed globe injury was more in males (88\%) and in females about 12\%(fig 2).

\begin{tabular}{|c|c|c|}
\hline $\begin{array}{c}\text { Base line IOP } \\
\text { (mm of Hg) }\end{array}$ & $\begin{array}{c}\text { No. of } \\
\text { Patients }\end{array}$ & $\begin{array}{c}\text { Percentile } \\
\text { (\%) }\end{array}$ \\
\hline $10-15$ & 6 & 24 \\
\hline $16-20$ & 7 & 28 \\
\hline $21-25$ & 7 & 28 \\
\hline $26-30$ & 2 & 8 \\
\hline$>30$ & 3 & 12 \\
\hline \multicolumn{2}{|c|}{ Table 2: Base line IOP at the time of 1 ${ }^{\text {st }}$ visit to hospital } \\
\hline
\end{tabular}

\begin{tabular}{|c|c|c|c|c|c|c|c|}
\hline $\begin{array}{c}\text { IOP } \\
\text { (mm 0f Hg) }\end{array}$ & $\begin{array}{c}\mathbf{1}^{\text {st }} \\
\text { month }\end{array}$ & $\begin{array}{c}\mathbf{2}^{\text {nd }} \\
\text { month }\end{array}$ & $\begin{array}{c}\mathbf{3}^{\text {rd }} \\
\text { month }\end{array}$ & $\begin{array}{c}\mathbf{6}^{\text {th }} \\
\text { month }\end{array}$ & $\begin{array}{c}\mathbf{1 2} \\
\text { months }\end{array}$ & $\begin{array}{c}\mathbf{1 8} \\
\text { months }\end{array}$ & $\begin{array}{c}\mathbf{2 4} \\
\text { months }\end{array}$ \\
\hline $10-15$ & 8 & 8 & 10 & 10 & 10 & 12 & 12 \\
\hline $16-20$ & 6 & 6 & 7 & 13 & 14 & 12 & 11 \\
\hline $21-25$ & 8 & 8 & 7 & 2 & 1 & 1 & 2 \\
\hline $26-30$ & 2 & 2 & 1 & 0 & 0 & 0 & 0 \\
\hline$>30$ & 1 & 1 & 0 & 0 & 0 & 0 & 0 \\
\hline
\end{tabular}

Base line IOP $>21 \mathrm{~mm}$ of $\mathrm{Hg}$ were measured in $48 \%$ of patients (Table 3 ). Out of $48 \%$ of patients who had base line IOP $>21$ $\mathrm{mm}$ of $\mathrm{Hg}$ at the end 3 month of follow up $32 \%$ of patients maintained the IOP $>21 \mathrm{~mm}$ of $\mathrm{Hg}$, they were treated with topical antiglaucoma drugs and IOP was controlled in all cases except two cases(Table 4).

GONIOSCOPY : Out of 25 patients examined 17 patients (68\%) were found to have varying degree of angle recession and 8 patients (32\%) with closed globe injury had no angle recession (fig 3, table 5, 6).

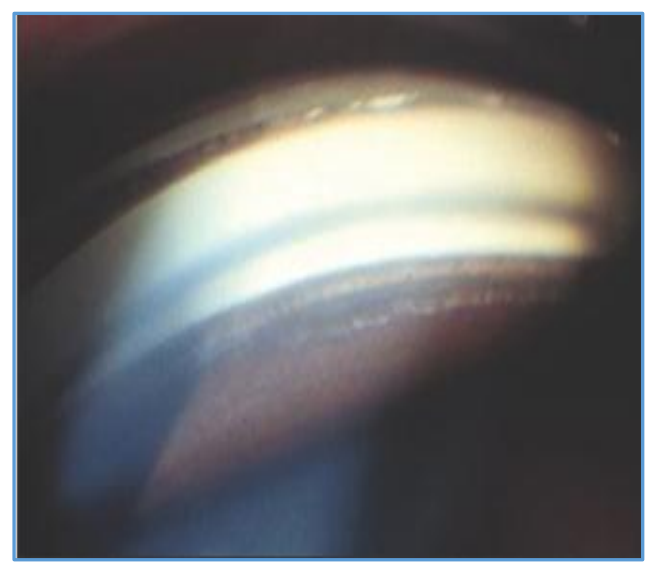

Fig. 3: Gonioscopy showing angle recession in inferior quadrant 


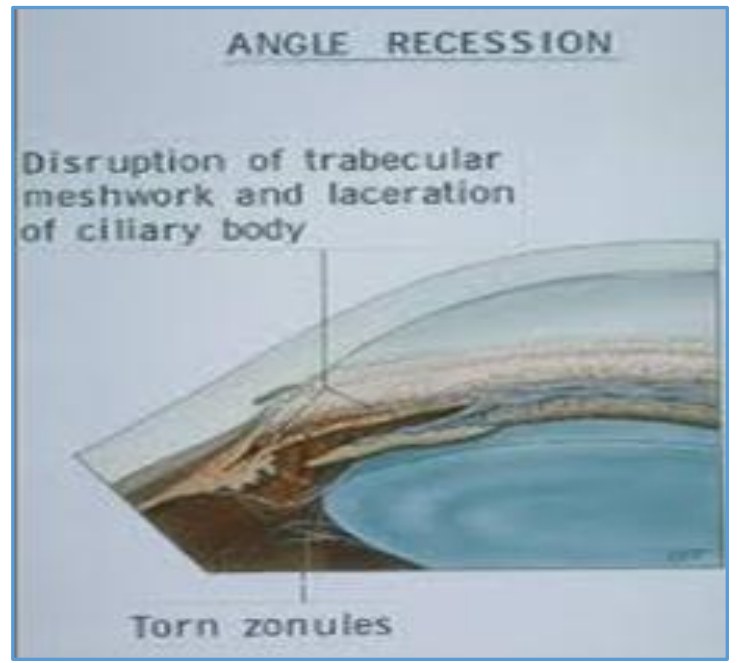

Fig. 4: schematic diagram of angle recession

\begin{tabular}{|c|c|c|}
\hline Angle recession & No. & Percent \\
\hline Present & 17 & 68 \\
\hline Absent & 8 & 32 \\
\hline Total & 25 & 100 \\
\hline \multicolumn{2}{|c|}{ Table 4: Gonioscpic finding in 25 cases examined } \\
after closed globe injury \\
\hline
\end{tabular}

\begin{tabular}{|c|c|c|c|c|}
\hline Circum. extent & $\mathbf{< 9 0}^{\circ}$ & $\mathbf{9 0}^{\circ} \mathbf{-} \mathbf{1 8 0}^{\circ}$ & $\mathbf{1 8 0}^{\circ} \mathbf{- 2 7 0}$ & $\mathbf{2 2 7 0}^{\circ}$ \\
\hline No. Of cases & 2 & 3 & 5 & 7 \\
\hline Per cent. & 8 & 12 & 20 & 28 \\
\hline \multicolumn{6}{|c|}{ Table 5: Circumferential extent of } \\
angle recession in 17 out of 25 cases \\
\hline
\end{tabular}

\begin{tabular}{|c|c|c|}
\hline Clinical Findings & No. of cases & Per cent \\
\hline Hyphema & 6 & $24 \%$ \\
\hline Sphincter tear & 7 & $28 \%$ \\
\hline Iridodialysis & 2 & $8 \%$ \\
\hline Subluxation of lens & 1 & $4 \%$ \\
\hline Traumatic cataract & 5 & $20 \%$ \\
\hline Choroidal tear & 2 & $8 \%$ \\
\hline Macular oedema & 2 & $8 \%$ \\
\hline \multicolumn{2}{|c|}{ Table 6: Anterior and posterior segment findings } \\
\hline
\end{tabular}

